\title{
Endotracheal tube verification in adult mechanically ventilated patients
}

\author{
P Jordan, PhD; W Ten Ham, PhD; D Fataar, RN, CCN \\ School of Clinical Care Sciences, Nelson Mandela Metropolitan University, Port Elizabeth, South Africa
}

Corresponding author: P Jordan (portia.jordan@nmmu.ac.za)

\begin{abstract}
Objective. To explore the methods that can be used to verify endotracheal tube (ETT) placement in adult mechanically ventilated patients. Methods. An integrative literature search was conducted in $2012-2013$ of research citations published in English on the topic of discussion. Electronic databases searched were: the Cumulative Index of Nursing and Allied Health (CINAHL), MEDLINE, PubMed, the Joanna Briggs Institute (JBI) systematic review library, the Cochrane Library and the National Guidelines Clearinghouse. In addition, reference lists of articles, conference summaries and hand searching was performed. Citations were selected based on the inclusion and exclusion criteria as decided upon by the researchers. The process of critical appraisal was done by the researchers as well as an independent reviewer, all skilled in the research methodology and subject matter related to the topic of discussion. A total of 45 articles were included for critical appraisal. On completion of the critical appraisal, which was done by two independent reviewers, 34 articles were excluded and 11 articles were included in the integrative review analyses. Data were extracted following the critical appraisal process. Owing to the heterogeneity of studies, a metasynthesis could not be done.

Results. Based on the reviewed studies, various methods have been identified to verify ETT placement in adult mechanically ventilated patients, namely ultrasonography, the use of centimetre scale printed on the ETT, manual cuff palpation, bilateral auscultation of chest and palpation of symmetrical chest movements, oesophageal detector devices, visualisation of the ETT, use of chest X-ray, pulse oximetry and capnography. Both ultrasonography and capnography had excellent sensitivity and specificity in verifying ETT placement. Conclusion. Although there are various methods reported for ETT verification, the review results recommended ultrasonography and capnography as the most accurate and reliable verification methods.
\end{abstract}

S Afr J Crit Care 2015;31(1):20-23. DOI:10.7196/SAJCC.199

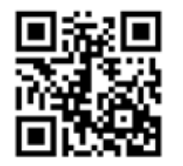

Mechanical ventilation is a lifesaving treatment modality, used most commonly in critical care units. A retrospective cohort over a defined period from six states in the USA reported that of 6469674 hospitalisations, $180326(2.8 \%)$ received invasive mechanical ventilation. The estimated national cost related to mechanical ventilation was USD27 billion, representing $12 \%$ of all hospital costs. ${ }^{[1]}$ A paucity of literature exists with regard to South African statistics related to the incidence and cost of mechanical ventilation in critical care units.

In order to mechanically ventilate critically ill patients, an endotracheal tube (ETT), the most commonly used artificial airway ${ }_{1}^{[2]}$ has to be inserted into the patient's trachea. ETT intubation has been classified as a highly technical and clinical skill that is accompanied by the danger of complications. These complications can occur during the intubation procedure, while the ETT is in place or after the ETT has been removed. Incorrect placement of the ETT may lead to inadequate ventilation, displacement, aspiration, ineffective oxygenation, hypoxia, hypotension and oesophageal intubation. Verification of the ETT in mechanically ventilated patients is therefore important. ${ }^{[3-8]}$ Different methods can be used to verify the placement of the ETT.

\section{Objective}

To search for evidence on the methods to verify ETT placement in adult mechanically ventilated patients.

\section{Methods \\ Literature search}

The search strategy was designed to access both published and unpublished literature, and was conducted by $D$ Fataar under supervision of an experienced researcher (P Jordan).

\section{Electronic search}

An initial search was done to identify relevant keywords contained in the titles of research studies found. Thereafter, a specific search was done using the following electronic databases: Cumulative Index of Nursing and Allied Health (CINAHL), EBSCOhost, MEDLINE (via PubMed), the Joanna Briggs Institute (JBI) systematic review library, the Cochrane Library, the National Guidelines Clearinghouse and internet searching engines (Google and Google Scholar). A combination of search terms was used to search the literature:'verification of endotracheal OR tracheal tube placement; 'complications AND incorrect endotracheal tube placement'; 'critical care AND endotracheal tube placement'; 'full text journal articles related to endotracheal tube placement AND verification'; 'endotracheal tube placement AND adults NOT neonates'; 'ventilation AND verification of endotracheal tubes'.

\section{Hand searching relevant journals}

Hand searching through the contents pages of journals pertaining to critical care nursing and medicine helped to identify any relevant evidence. 


\section{Grey literature}

The search for grey literature was to ensure that unpublished research on the topic was consulted. University databases were searched for unpublished treatises and theses. Reference lists and bibliographies of potential eligible articles and summaries of conference proceedings were searched, and authors known in the field were contacted to enquire if there were any data findings that were pending for publication.

\section{Inclusion criteria}

The types of studies included in this review were evaluated according to the study design and classified from Level I to VI as described by LoBiondo-Wood and Haber $^{[9]}$ (Table 1). Studies with human, adult patients older than 18 years, and who were intubated and attached to a mechanical ventilator in a critical care unit were included. Interventions related to the verification of the ETT placement in the patient were considered.

\section{Exclusion criteria}

All studies that focused on paediatric patients and neonates, as well as animal studies were excluded, as there are anatomical and physiological differences between these population groups.

\section{Critical appraisal}

The methodological rigour of the included studies was assessed using the critical appraisal tools available in the JBI SUMARI software packages, version 4.0 (Joanna Briggs Institute, Australia). The MAStARI (JBI Meta-analysis of Statistics Assessment and Review Instrument) was used for critical appraisal process. Two reviewers, who are experts in critical care, independently appraised the studies found using the selected appraisal tools. Once the reviews were done independently, the JBI system was used to extract and consolidate the results.

\section{Data extraction}

Information on the author, journal, publication date, setting, sample size, intervention, outcomes, allocation concealment, loss to follow-up, appropriate statistics and adequate follow-up were extracted by D Fataar, using the appropriate data extraction tools as per the JBI-MAStARI version 4.0 software package. The extraction process was verified by the current author (P Jordan).

\section{Table 1. Evidence hierarchy for rating levels of evidence associated with study design ${ }^{[9]}$}

\begin{tabular}{ll}
\hline Level & Description \\
\hline I & Systematic review or meta-analysis of RCTs \\
II & Evidence-based clinical practice guidelines based on systematic reviews \\
III & Quasi-experimental study \\
IV & $\begin{array}{l}\text { Non-experimental study (survey, case-control, case study, cohort, observational, } \\
\text { prospective, correlation) }\end{array}$ \\
V & Systematic reviews of descriptive and qualitative studies \\
VI & Single descriptive or qualitative study \\
VII & Opinion of authorities and/or reports of expert committees \\
RTC = randomised control trial
\end{tabular}

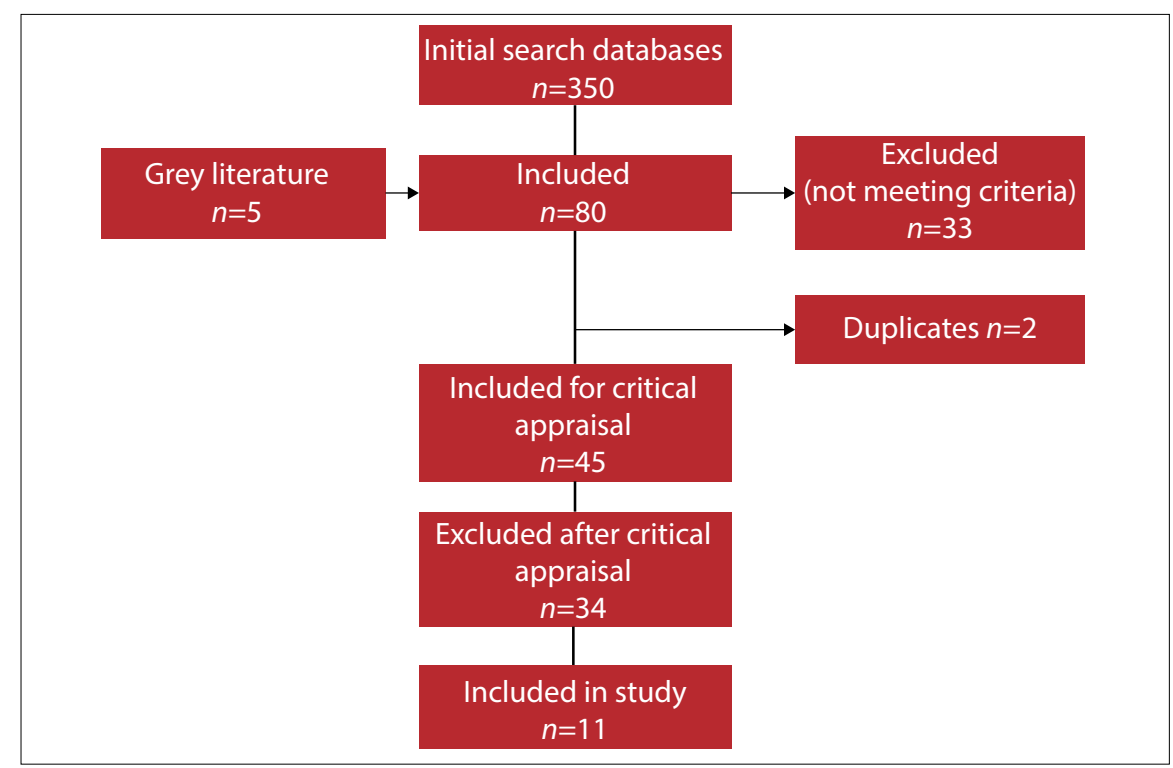

Fig. 1. PRISMA

\section{Ethical considerations}

Although the ethical principles of beneficence, respect for human dignity and justice were not directly applicable to an integrativeliterature review, ethicalapproval to conduct the study was nevertheless obtained by the ethics committee of the university where the study was conducted (ethics number: H11-HEA-NUR-007).

\section{Results}

The initial search delivered 350 articles, of which five were obtained from grey literature; the majority of the other articles were obtained from Google Scholar and PubMed. After exclusion due to not being relevant to the topic of discussion, 80 articles were included. After the second screening was done, another 35 articles were excluded as there were two duplicates, and the other 33 articles did not answer the research question. A total of 45 articles were included for critical appraisal.Basedonthecriticalappraisal results of the researcher and independent reviewer,
34 of these articles were excluded, with only 11 articles included in the integrative review analyses. The selection process of the studies is outlined in Fig. 1.

The characteristics of the 11 included articles (Level II $n=3$, Level IV $n=8$ ) are presented in Table 2.

\section{Discussion}

From the data analysed, different methods were identified to verify ETT placement in adult mechanically ventilated patients. The accuracy of any technique to identify correct ETT placement is based on its sensitivity (ability to detect whenever tracheal intubation does occur) and specificity (ability to detect whenever tracheal intubation does not occur).

\section{Ultrasonography}

Two of the 11 studies, which were both randomised controlled trials, reported that ultrasonography is a reliable verification method; Muslu et al. ${ }^{[10]}$ reported $100 \%$ 
Table 2. Characteristics of 11 studies reviewed

\begin{tabular}{|c|c|c|c|c|}
\hline Study & Setting and participants & Study design & Intervention & Verification methods identified \\
\hline $\begin{array}{l}\text { Muslu et } \\
\text { al., } 2011^{[10]}\end{array}$ & $\begin{array}{l}150 \text { adult patients who were } \\
\text { scheduled for elective surgery } \\
\text { and postop ICU admittance }\end{array}$ & $\begin{array}{l}\text { RCT } \\
\text { (Level II) }\end{array}$ & $\begin{array}{l}\text { Two treatment groups to } \\
\text { investigate the use of sonography } \\
\text { for ETT confirmation }\end{array}$ & $\begin{array}{l}\text { Ultrasonography was reported as an effective } \\
\text { method to confirm ETT placement (100\% sensitive } \\
\text { and } 100 \% \text { specific). }\end{array}$ \\
\hline $\begin{array}{l}\text { Werner et al., } \\
2007^{[11]}\end{array}$ & $\begin{array}{l}33 \text { adult ICU patients who } \\
\text { underwent elective surgery }\end{array}$ & $\begin{array}{l}\mathrm{RCT} \\
\text { (Level II) }\end{array}$ & $\begin{array}{l}\text { Two treatment groups to evaluate } \\
\text { the accuracy of ultrasonography in } \\
\text { confirming ETT placement }\end{array}$ & $\begin{array}{l}\text { Ultrasonography was } 100 \% \text { sensitive and } 97 \% \\
\text { specific in accurately verifying ETT placement. }\end{array}$ \\
\hline $\begin{array}{l}\text { Sitzwohl et } \\
\text { al., 2010 }\end{array}$ & $\begin{array}{l}160 \text { adult ICU patients who } \\
\text { underwent elective surgery }\end{array}$ & $\begin{array}{l}\mathrm{RCT} \\
\text { (Level II) }\end{array}$ & $\begin{array}{l}\text { Eight study groups to compare } \\
\text { three different bedside methods } \\
\text { of verification of correct ETT } \\
\text { placement }\end{array}$ & $\begin{array}{l}\text { Bilateral auscultation of the chest, observation and } \\
\text { palpation of symmetrical chest movements, use of cm } \\
\text { scale printed on the tube and a combination of the } \\
\text { three methods were evaluated. The highest sensitivity } \\
\text { and specificity were obtained when combining all } \\
\text { three methods when verifying ETT placement. }\end{array}$ \\
\hline $\begin{array}{l}\text { Varshney et } \\
\text { al., } 2011^{[13]}\end{array}$ & $\begin{array}{l}200 \text { adult ICU patients who } \\
\text { underwent elective surgery }\end{array}$ & $\begin{array}{l}\text { Non- } \\
\text { experimental } \\
\text { study: } \\
\text { prospective } \\
\text { (Level IV) }\end{array}$ & $\begin{array}{l}\text { Using the centimetre scale } \\
\text { printed on the ETT as a } \\
\text { verification method for } \\
\text { placement }\end{array}$ & $\begin{array}{l}\text { The centimetre scale printed on the ETT can be used. } \\
\text { However, optimal depth of the ETT placement can be } \\
\text { estimated by a formula (height in centimetres/7 - } 2.5 \text { ); } \\
\text { the method is height dependent and should not be } \\
\text { used as a sole verification method. }\end{array}$ \\
\hline $\begin{array}{l}\text { Simpson et } \\
\text { al., 2012 }\end{array}$ & 794 ICU adult patients & $\begin{array}{l}\text { NEO } \\
\text { (Level IV) }\end{array}$ & $\begin{array}{l}\text { Assessing practices related to } \\
\text { ETT placements }\end{array}$ & $\begin{array}{l}\text { Capnography was recommended to confirm ETT } \\
\text { placements. }\end{array}$ \\
\hline $\begin{array}{l}\text { Delorio, } \\
2005^{[15]}\end{array}$ & $\begin{array}{l}550 \text { emergency physicians } \\
\text { involved in intubation of } \\
\text { ICU patients }\end{array}$ & $\begin{array}{l}\text { Non- } \\
\text { experimental: } \\
\text { survey (Level IV) }\end{array}$ & $\begin{array}{l}\text { Availability of capnography as a } \\
\text { method to confirm ETT placement }\end{array}$ & $\begin{array}{l}\text { Although capnography was the recommended } \\
\text { method for ETT verification, it is not widely } \\
\text { available or consistently used. }\end{array}$ \\
\hline $\begin{array}{l}\text { Dittrich, } \\
2002^{[16]}\end{array}$ & $23 \mathrm{ICU}$ patients & $\begin{array}{l}\text { Non- } \\
\text { experimental: } \\
\text { case study } \\
\text { (Level IV) }\end{array}$ & $\begin{array}{l}\text { Evaluating clinical methods } \\
\text { (auscultation and palpation of } \\
\text { chest), cuff palpation, CXR, pulse } \\
\text { oximetry, capnography and EDD as } \\
\text { verification methods }\end{array}$ & $\begin{array}{l}\text { Among the verification methods explored, } \\
\text { capnography was the most reliable, sensitive } \\
\text { and specific method to confirm ETT placement } \\
\text { (sensitivity of } 93 \% \text { and specificity of } 97 \% \text { ). }\end{array}$ \\
\hline $\begin{array}{l}\text { Grmec, } \\
2002^{[17]}\end{array}$ & $\begin{array}{l}345 \text { adult intubated ICU } \\
\text { patients }\end{array}$ & $\begin{array}{l}\text { NEO } \\
\text { (Level IV) }\end{array}$ & $\begin{array}{l}\text { Comparing three methods: } \\
\text { auscultation, capnography and cap- } \\
\text { nometry to confirm ETT placement }\end{array}$ & $\begin{array}{l}\text { Of three methods tested, capnography was the } \\
\text { most reliable method to confirm ETT placement in } \\
\text { emergency conditions. }\end{array}$ \\
\hline $\begin{array}{l}\text { Ledrick et } \\
\text { al., 2008 }\end{array}$ & $163 \mathrm{ICU}$ intubated patients & $\begin{array}{l}\text { NEO } \\
\text { (Level IV) }\end{array}$ & $\begin{array}{l}\text { Evaluating manual cuff palpation as } \\
\text { a method to confirm ETT placement }\end{array}$ & $\begin{array}{l}\text { Manual cuff palpation can be used as a verification } \\
\text { method; however, the use of this method is limited } \\
\text { and not recommended as a sole method. }\end{array}$ \\
\hline $\begin{array}{l}\text { Takeda, et } \\
\text { al., 2003 }\end{array}$ & 137 ICU intubated patients & $\begin{array}{l}\text { NEP } \\
\text { (Level IV) }\end{array}$ & $\begin{array}{l}\text { Assessing three methods, namely } \\
\text { the use of clinical signs, capnography } \\
\text { and EDD to verify ETT placement }\end{array}$ & $\begin{array}{l}\text { Of three methods assessed, capnography was the } \\
\text { most reliable method of verifying ETT placement } \\
\text { in non-cardiac arrest patients. }\end{array}$ \\
\hline $\begin{array}{l}\text { Hussain et } \\
\text { al., 2006 } 200]\end{array}$ & $\begin{array}{l}400 \text { intubated adult } \\
\text { patients }\end{array}$ & $\begin{array}{l}\text { NEP } \\
\text { (Level IV) }\end{array}$ & $\begin{array}{l}\text { Efficacy of EDDs as a verification } \\
\text { method }\end{array}$ & $\begin{array}{l}\text { The use of EDD as a verification method shown to } \\
\text { be effective. }\end{array}$ \\
\hline
\end{tabular}

sensitivity and specificity and Werner et al. ${ }^{[1]}$ reported $100 \%$ sensitivity and $97 \%$ specificity. The use of ultrasound may be limited by availability of both expertise and equipment.

\section{Using centimetre scale printed on the ETT}

Sitzwohl et al. ${ }^{[12]}$ explored three methods, namely the use of bilateral auscultation of the chest, observation and palpation of symmetrical chest movements, and the use of centimetre scale printed on the ETT. Their study showed that among single tests, the best way of excluding endobronchial intubations with the highest sensitivity was by observing the centimetre scale on the ETT. However, when all three bedside methods were combined, sensitivity was higher than observing the centimetre scale alone. Varshney et al. ${ }^{[13]}$ reported in their study that the centimetre scale printed on the ETT could be used as a verification method. They suggested that optimal depth of the ETT placement could be estimated by means of a formula: height in $\mathrm{cm} / 7-2.5$. The study further recommended the $21 / 23 \mathrm{~cm}$ rule, i.e. a correct depth of $21 \mathrm{~cm}$ for women and $23 \mathrm{~cm}$ in men when checking the ETT length. According to their study, the method is height dependent and should not be used as the sole verification method. As only two studies were found that highlighted this verification method, more research is needed to confirm this method for verification of ETT placement.

\section{Manual cuff palpation}

Two of the 11 studies highlighted the use of ballottement, or manual cuff palpation, to determine if the tube is at the correct depth. This involves palpating the pilot balloon by applying pressure in the suprasternal notch. Manual cuff palpation is a simple technique, but is limited in identifying intubations of appropriate depth. Ballottement was also found to lead to complications due to pain and unwanted rise in both blood and intracranial pressures, and is therefore not recommended for use in the critical care setting..$^{[13,18]}$ This method is thus not recommended for ETT placement verification. 


\section{Bilateral auscultation of chest and palpation of symmetrical chest movements}

Bilateral auscultation of the chest can be done to identify and prevent possible endobronchial intubation. Although auscultation of the lungs can be used to verify the position of the ETT, it may be deceptive in patients with decreased lung compliance or in patients who experience severe bronchospasm. ${ }^{[12]}$ In false negative results by auscultation, examiners did not clearly hear breath sounds and did not see good chest wall excursions because of obesity, or breath sounds were mistakenly identified as stomach gurgling in some clinical conditions such as pulmonary oedema, excessive secretions or aspiration. ${ }^{[17,19]}$ Auscultation is a common method to ensure correct placement of the ETT; however, it is inaccurate when used alone and by inexperienced examiners. Furthermore, auscultation does not reveal how well the lungs are functioning and whether or not blood is being oxygenated effectively for gaseous exchange. ${ }^{[17]}$ Auscultation and palpation of symmetrical chest movements are most reliable when used with other methods, such as capnography. ${ }^{[13,17]}$

\section{Capnography}

Five of the 11 studies (all observational) recommended capnography as the most reliable method for confirming ETT placement in all settings, including the operating theatre. ${ }^{[14-17,19]}$ According to Simpson et al., ${ }^{[14]}$ capnography should be used to confirm ETT position in all intubations, including those performed outside the operating theatre. ${ }^{[13]}$ Delorio ${ }^{[15]}$ confirmed that capnography is the recommended method for ETT verification, but also recognised that the use of capnography is limited and is often either not available or inconsistently applied in ETT verification. Dittrich ${ }^{[16]}$ confirmed that capnography is the most reliable method for verification of the ETT. This study showed that of three methods explored, capnography had the highest sensitivity (93\%) and specificity (97\%). An advantage of using capnography is that the method may be more easily applied without the need for specific expertise, compared with ultrasound.

\section{EDDs}

It has been reported in three of the 11 studies that EDDs, consisting of either a self-inflating bulb or a $60 \mathrm{~mL}$ syringe, have become one of the simplest methods to confirm ETT placement. In a prospective study by Hussain et al., ${ }^{[20]}$ it was shown that EDD s had a sensitivity, specificity and positive predictive value of discriminating oesophageal from endotracheal intubation of nearly $100 \%$ in healthy adults who were intubated. The effectiveness of this method can be affected by the rigidity and structural differences of the trachea, as well as secretions, vomit, blood or any other fluids in the airway. ${ }^{[16,19,20]}$ During cardiac arrest, negative results caused by the use of this method are not uncommon and clinical methods should then be applied as an adjunct method of verification. EDDs appear to be highly reliable in controlled settings such as the operating theatre, but should be used with greater caution in other settings.

\section{Other methods}

The use of chest radiographs as a method to verify ETT placement is not recommended due to a delay between taking the film and having the film developed, as well as possible incorrect interpretation. ${ }^{[16]}$ Pulse oximetry could be used in verifying ETT position if there is a perfusing rhythm. However, desaturation is usually a late indicator of deterioration in the patient's condition and its use as a rapid indicator of oesophageal intubation is inadequate. Pulse oximetry requires adequate peripheral perfusion, and is of limited utility in shocked, hypovolaemic and vasoconstricted patients. ${ }^{[16,19]}$ These two methods are the least recommended ETT position verifiers. Visualisation of the ETT is implicitly mentioned in two studies as a method of verification of the ETT. However, this method might not be possible due to trauma, bleeding, vomitus, secretions or oedema and is not without potential hazards. ${ }^{[17,19]}$ Direct visualisation should be the first confirmatory method, as the practitioner can assure that the tube is in the correct place, as it has incomparable speed and achievement rates when compared with some of the alternative methods of placing ETTs. ${ }^{[19]}$

\section{Study limitations}

The integrative literature review was conducted using a standard method for literature review, but statistical synthesis of quantitative data was not possible. Due to the heterogeneity of study interventions and levels of evidence used, meta-analysis of data was not possible.

\section{Conclusion}

Various methods have been identified to verify ETT placement in adult mechanically ventilated patients: ultrasonography, the use of centimetre scale printed on the ETT, manual cuff palpation, bilateral auscultation of chest and palpation of symmetrical chest movements, EDDs, visualisation of the ETT, use of CXR, pulse oximetry and capnography. Both ultrasonography and capnography were found to be highly sensitive and specific for verifying ETT placement, and are recommended for clinical practice.

References

1. Wunsch $H$, Linde-Zwirble WT, Angus DC, Hartman ME, Milbrandt EB, Khan JM. The epidemiology of mechanical ventilation in the United States. Crit Care Med 2010;38(10):19471953. [http://dx.doi.org/10.1097/CCM.0b013e318ef4460]

2. Estaban A, Anzueto A, Alia I, et al. How is mechanical ventilation employed in the critical care unit? An international utilization review. Am J Respir Crit Care Med 2000;161(5):1450-1458. unit? An international utilization review. Am J Respir
[http://dx.doi.org/10.1164/ajrccm.161.5.9902018]

3. Griesdale DE, Bosma TL, Kurth T, Isac G, Chittock DR. Complications of endotracheal intubation in the critically ill. Intensive Care Med 2008;34(1):1835-1842. [http://dx.doi.org/10.1007/s00134-008-1205-6]

4. Jaber S, Amraoui J, Lefrant JYI. Clinical practice and risk factors for immediate complications of endotracheal intubation in the intensive care unit: A prospective, multiple-center study. Crit Care Med 2006;34(9):2355-2361. [http://dx.doi.org/10.1097/01.CCM.0000233879.58720.87]

5. Bowles TM, Freshwater-Turner DA, Janssen DJ, Peden CJ; the RTIC Severn Group. Out-oftheatre tracheal intubation: Prospective multicenter study of clinical practice and adverse events. Br J Anesth 2011;107(5):687-692. [http://dx.doi.org/10.1093/bja/aer251]

6. Sitzwohl C, Langheinrich A, Schober A, et al. Endobronchial intubation detected by insertion depth of endotracheal tube, bilateral auscultation, or observation of chest movements: Randomised trial. BMJ 2010;41:c5943 [http://dx.doi.org/10.1136/bmj.c5943]

7. Salem MR. Verification of endotracheal tube position. Anesthesiol Clin North America 2001;19(4):813-839.

8. Angelotti T, Weiss EL, Lemmens HJM, Brock-Utne J. Verification of endotracheal tube placement by professional providers: Is a portable fiberoptic bronchoscope of value? Air Med J 2006;25(2):74-80. [http://dx.doi.org/10.1016/j.amj.2005.12.001]

9. LoBiondo-Wood G, Haber J. Nursing Research: Methods and Critical Appraisal for Evidencebased Practice. 7th ed. St Louis, USA: Mosby, 2010.

10. Muslu B, Sert H, Kaya A, et al. Use of sonography for rapid identification of oesophageal and tracheal intubations in adult patients. J Ultrasound Med 2011;30(5):671-676.

11. Werner SL, Smith CE, Goldstein JR, Jones RA, Cydulka RK. Pilot study to evaluate the accuracy of ultrasound in confirming endotracheal tube placement. Ann Emerg Med 2007;49(1):75-80. [http://dx.doi.org/10.1016/j.annemergmed.2006.07.004]

12. Sitzwohl C, Kettner S, Langheinrich A, Schoenberg C, Weinstabl C. Performance of three different bedside methods to detect inadvertent endobronchial intubation. Anesthesiology 2010;105:A532.

13. Varshney M, Sharma K, Kumar R, Varshney PG. Appropriate depth of placement of oral endotracheal tube and its possible determinants in Indian adult patients. Indian J Anaesth 2011;55(5):488-493. [http://dx.doi.org/10.4103/0019-5049.89880]

14. Simpson GD, Ross MJ, McKeown DW, Ray DC. Tracheal intubation in the critically ill: A multicentre national study of practice and complications. Br JAnaesth 2012;108(5):792-799. [http:// dx.doi.org/10.1093/bja/aer504]

15. Delorio NM. Continuous end-tidal carbon dioxide monitoring for confirmation of endotracheal tube placement is neither widely available nor consistently applied by emergency physicians. Emerg Med J 2005;22(7):490-493. [http://dx.doi.org/10.1136/emj.2004.015818]

16. Dittrich KC. Delayed recognition of oesophageal intubation. Can J Emerg Med 2002;4(1):41-44.

17. Grmec S. Comparison of three different methods to confirm tracheal tube placement in emergency intubation. Intensive Care Med 2002;28(6):701-704. [http://dx.doi.org/10.1007/s00134-002-1290-x]

18. Ledrick D, Plewa M, Casey K, Taylor J, Buderer N. Evaluation of manual cuff palpation to confirm proper endotracheal tube depth. Prehosp Disaster Med 2008;23(3):270-274.

19. Takeda T, Tanigawa K, Tanaka H, Hayashi Y, Goto E, Tanaka, K. The assessment of three methods to verify tracheal tube placement in the emergency setting. Resuscitation 2003;56(2):153-157. [http://dx.doi.org/10.1016/S0300-9572(02)00345-3]

20. Hussain N, Jaffri A, Siddiqi R. Efficacy of oesophageal detector device in verification of endotracheal tube placement. Pak Armed Forces Med J 2006;1(3):1-4. 